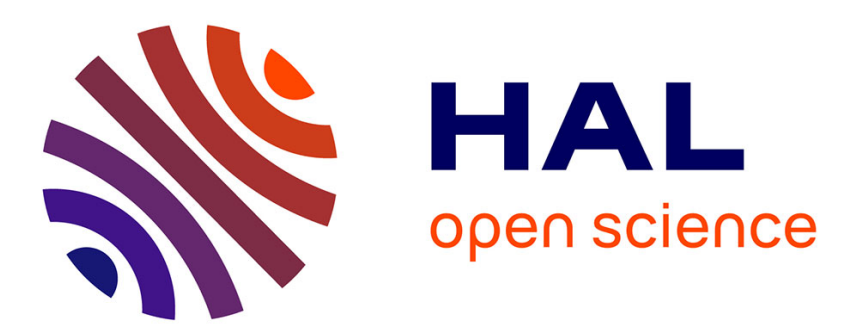

\title{
Assessment of soot particle-size imaging with LII at Diesel engine conditions
}

Emre Cenker, K Kondo, Gilles Bruneaux, T Dreier, T Aizawa, C Schulz

\section{To cite this version:}

Emre Cenker, K Kondo, Gilles Bruneaux, T Dreier, T Aizawa, et al.. Assessment of soot particle-size imaging with LII at Diesel engine conditions. Applied Physics B Photophysics and Laser Chemistry, 2015, 119 (4), pp.765-776. 10.1007/s00340-015-6106-0 . hal-01176511

\section{HAL Id: hal-01176511 \\ https://hal.science/hal-01176511}

Submitted on 15 Jul 2015

HAL is a multi-disciplinary open access archive for the deposit and dissemination of scientific research documents, whether they are published or not. The documents may come from teaching and research institutions in France or abroad, or from public or private research centers.
L'archive ouverte pluridisciplinaire HAL, est destinée au dépôt et à la diffusion de documents scientifiques de niveau recherche, publiés ou non, émanant des établissements d'enseignement et de recherche français ou étrangers, des laboratoires publics ou privés. 


\title{
Assessment of soot particle-size imaging with LII at Diesel engine conditions
}

\author{
E. Cenker ${ }^{1,2,3}(\bowtie)$, K. Kondo ${ }^{4}$, G. Bruneaux ${ }^{1,2}$, T. Dreier $^{3}$, T. Aizawa $^{4}$ and C. Schulz $^{3}$ \\ ${ }^{1}$ IFP Energies Nouvelles, 1 et 4 avenue de Bois-Préau, 92852 Rueil-Malmaison, France; Institut Carnot \\ IFPEN Transports Energie \\ 2 École Centrale Paris, Chatenay-Malabry, France \\ ${ }^{3}$ Institute for Combustion and Gas Dynamics - Reactive Fluids (IVG) and Center for Nanointegration \\ Duisburg-Essen (CENIDE), University of Duisburg-Essen, Duisburg, Germany \\ ${ }^{4}$ Meiji University, Tokyo, Japan \\ emre.cenker@uni-due.de (corresponding author)
}

\begin{abstract}
Two-time-step laser-induced incandescence (LII) imaging was performed in Diesel engine-relevant combustion to investigate its applicability for spatially-resolved measurements of soot primary particle sizes. The method is based on evaluating gated LII signals acquired with two cameras consecutively after the laser pulse and using LII modeling to deduce the particle size from the ratio of local signals. Based on a theoretical analysis, optimized detection times and durations were chosen to minimize measurement uncertainties. Experiments were conducted in a high-temperature high-pressure constant-volume precombustion vessel under the Engine Combustion Network's (ECN) "Spray A" conditions at 61-68 bar with additional parametric variations of injection pressure, gas temperature, and composition. The LII measurements were supported by pyrometric imaging measurements of particle heat-up temperatures. The results were compared to particle-size and size-dispersion measurements from transmission electron microscopy (TEM) of soot thermophoretically sampled at multiple axial distances from the injector. The discrepancies between the two measurement techniques are discussed to analyze uncertainties and related error sources of the two diagnostics. It is found that in such environment where particles are small and pressure is high, LII signal decay times are such that LII with standard nanosecond laser and detector equipment suffers from a strong bias towards large particles.
\end{abstract}

\section{Keywords}

Soot particle size, LII imaging, TEM, pyrometry imaging 


\section{Introduction}

Direct-Injection (DI) systems (Diesel and gasoline) are becoming the dominant technology in internal combustion engines in the European market due to their improved fuel economy compared to conventional engine concepts [1]. Soot emission, however, can be significant in these engines because regions of high fuel concentration are generated and can lead to soot formation during the combustion process. In order to restrain the adverse effects of soot on human health [2,3] and environment [4], legislation sets stringent limits for the emission of particulate matter in the transportation sector. Meeting these regulations requires the understanding of formation, growth, aggregation, and oxidation of soot. A quantitative understanding of these processes enables the development and the validation of soot models for CFD (computational fluid dynamics) simulations and to develop methodologies to limit pollutant emissions. Measuring primary particle sizes and their spatial distribution with laser-based in situ techniques during Diesel combustion is of high interest for understanding these processes and for generating data bases for model validation.

The aim of this study is to optimize two-dimensional particle sizing via laser-induced incandescence (LII) imaging in an engine-relevant high-temperature high-pressure constant-volume pre-combustion vessel and to assess its applicability in comparison to results of sampling measurements. LII particle-sizing is based on the fact that, after heating the particles with a nanosecond laser pulse, small particles cool down faster than larger ones due to their larger surface-to-volume ratio and therefore provide signal with different decay times [5]. Quantitative particle-size information can be obtained from a best-fit comparison of the temporal signal decay and simulations based on the particles' energy and mass balance equations $[6,7]$. While recording signal traces with fast multipliers is well-established for point measurements (time-resolved LII, TiRe-LII, e.g., $[5,7,8]$ ), the transfer to two-dimensional imaging through two-time-step LII imaging was first demonstrated by Will et al. [9], and later used in ref. [1013]. Here, LII signals are acquired at two delay times after the laser pulse with gated intensified cameras and the particle size is deduced from the local signal ratio. The loss in temporal information, however, reduces accuracy and precision of the resulting particle size measurements. This method is therefore only of interest when instantaneous two-dimensional information is needed - such as in a highly fluctuating Diesel spray combustion.

In a preliminary study [14], LIISim $[15,16]$ was used for modeling LII signals for the relevant conditions to determine optimized diagnostics strategies for particle size imaging with two detection windows based 
on libraries of simulated signals. In the present work, particle heat-up temperatures were measured by two-color pyrometry to determine the appropriate laser fluence for an optimal particle heating that provides strong LII signal while minimizing soot evaporation. And the two-time-gate particle-sizeimaging strategy was applied to sooting Diesel combustion processes. The experiments were conducted for the Diesel engine-relevant "Spray A" conditions that have been investigated within the Engine Combustion Network (ECN) with a multitude of diagnostics and simulations [17-20]. Additional parametric variations in pressure, temperature, and gas composition were carried out to analyze their effects on the evaluated soot particle size and its spatial distribution. The LII results were compared to particle-size and size-distribution measurements by transmission electron microscopy (TEM) of thermophoretically-sampled soot at multiple axial distances from the nozzle.

\section{Methodology}

TiRe-LII is an optical in situ technique for measuring the particle size. Soot particles are heated via absorption of light from a laser pulse to temperatures above $3000 \mathrm{~K}$ and the subsequent blackbody radiation is recorded during the cooling phase. In a quantitative approach, assuming that all soot primary particles are spheres, the temperature and size of any known particle size can be modeled for any given time by solving the energy and mass balances. As a consequence, the size of a particle can be evaluated from the temporally-resolved temperature or incandescence signal by using a numerical scheme $[5,6]$. The methodology for modeling the temporal variation of LII signals is presented, e.g., in [7]. The effect of pressure is investigated in [21] and the LIISim code $[15,16]$ is used to assess all this information within the present work. The accuracy of particle-sizing from a measured TiRe-LII signal trace depends on the assumed conditions for ambient pressure, gas temperature, particle heat-up temperature, accommodation coefficients, soot morphology and optical properties. The particle heat-up temperature can either be calculated from the full modeling [22] of the heat-up process or determined via pyrometry immediately after the laser pulse [23]. For instantaneous in-cylinder measurements, such parameters vary spatially and temporally and simultaneous measurements are not possible. Therefore, it is important to determine measurement strategies that have the lowest possible dependence on these parameters.

\section{Particle-size imaging}


To deduce the primary particle size by LII from two time-gated detectors (intensified cameras) it is important to optimize the delays relative to the laser pulse and the integration times. Integration times not only influence the sensitivity of the signal ratio on particle size but also the level of interference from flame luminosity and the total signal and hence, the signal-to-noise ratio. In a setup where jitter between camera trigger and the laser pulse cannot be avoided completely, possible deviations in timing can cause considerable error. To minimize this, actual laser and camera timings should be monitored and these timings should be used in data evaluation. For each condition (in terms of the parameters influencing LII mentioned above) LII-signal traces were simulated for each particle-size class and then combined to describe the behavior of mono-disperse ensembles [24]. The simulated signal "libraries" are used to analyze the sensitivity of various combinations of detection and integration times. It is essential that both cameras capture different temporal information from the LII decay so that the ratio of both signals is a sensitive measure of the decay. Both images can be acquired either with various delays $[9,25]$ and/or gate widths $[26,27]$ within the signal decay. For each combination of delays and gate widths, signals and signal ratios can be computed by convoluting the temporal characteristics of the detectors with the respective LII signal library. The resulting simulated signal ratios of the two gated signals are then a unique function of the particle size and a lookup table can be created that is then used for the interpretation of measured ratios for each pixel. Further details on this evaluation can be found in ref. [14].

\section{Pyrometry}

The bathgas temperature and the heat-up temperature of soot must be known to solve the energy balance equations for the laser-heated soot particles. Multi-wavelength optical pyrometry [28-30] is a well-established emission-based technique and is used to determine the flame temperature in this work. The technique allows temporally- and under some conditions spatially-resolved measurements. Furthermore, unlike the laser-based methods, soot pyrometry can be used to measure the heat-up temperature of soot particles at any instant after the laser pulse in an LII measurement. The selection of detection wavelengths in soot pyrometry is a problem of a multivariable optimization and various factors affecting the detection system performance and the accuracy must be taken into account. Liu et al. showed how the detection wavelengths affect the sensitivity of the soot temperature measurement [31]. To achieve a better accuracy for soot temperature, it is desirable to use a shorter lower detection wavelength and a longer upper detection wavelength in the spectral range of about $400 \mathrm{~nm}$ to near 
infrared [31,32]. It is also recommended that the filter bandwidths are narrow compared to the spacing in between their center wavelengths.

One concern in soot pyrometry is the self-absorption of the incandescence signal on the detection path. The emissivity of soot, hence the absorption efficiency, is wavelength dependent [33] and therefore signals emitted at different wavelengths are subjected to different attenuation. Depending on the local soot concentration, soot pyrometry measurements may show systematic deviation from the actual temperature. Schraml et al. [32] performed extinction measurements to correct the Planck spectra for wavelength-dependent signal attenuation in a non-premixed flame with moderate optical thickness, and evaluated the error as $120 \mathrm{~K}$ in measured heat-up temperatures. For low or moderate soot volume fraction, the systematic error due to self-absorption is limited.

\section{LII at high pressure}

One major complication of TiRe-LII at high pressure is the very short signal lifetime due to fast heat exchange of the particles with their environment [34-36]. At 60 bar, the LII signal of a 20-nm particle decreases to $10 \%$ in less than 20 ns. In LII experiments with conventional nanosecond-pulsed lasers, particles reach the maximum temperature only after some delay ( $7 \mathrm{~ns})$. Within this period, particles already loose a significant fraction of the absorbed energy through heat conduction - at rates that depend on the particle size. Therefore, each particle-size class reaches a different peak temperature [37] causing a bias of the total signal towards large particles. Also, strategies for measuring the heat-up temperature like the two-color LII method [23] are affected by this effect and therefore do no longer provide the required information to initiate the modeling of the cooling process. Additionally, in timegated detection the contribution of small particles is weak (because of the reduced heat-up temperature) and vanishes quickly (because of the enhanced convective cooling already during signal collection) and the measured soot volume fractions systematically overlook the contribution of small particles. For particle sizes between 10 and $40 \mathrm{~nm}$, the difference in heat-up temperature at moderate laser fluence at 60 bar is above $500 \mathrm{~K}$ [14]. Because the radiation energy per unit time is proportional to the third power of the particle diameter, the signal contribution from the small particles, at least for the second delayed detection gate, is almost zero and the evaluated particle size is biased towards the largest particles. To avoid the complications of the particle-size dependence on the peak temperature, Charwath et al. [37] proposed faster short-pulse laser heating to temporally separate heat-up from particle cooling. However, Michelsen [38] reported that rapid heating with picosecond lasers brings new complications to the particle-sizing and requires new modeling approaches. Unconventional laser 
sources with pulse durations of $\sim 1$ ns would potentially be a good compromise, but they are not readily available and have not yet been explored for LII.

To ameliorate this non-uniform heat-up temperature distribution problem, in this work, instead of measuring heat-up temperatures, the LII signals were evaluated with modeling the heat-up of the particle ensemble which automatically includes the effects of particle-size-dependent temperature variations in the laser-heated particle ensemble. This approach, however, cannot prevent the effect that the measurement systematically neglects the contribution of the smallest particle fraction.

\section{Experiment}

\subsection{High-pressure high-temperature combustion cell}

The experiments were performed in an optically-accessible high-pressure high-temperature Diesel combustion vessel. The gas pressure, temperature, and species composition at the time of fuel injection were varied by pre-combustion of a $\mathrm{C}_{2} \mathrm{H}_{4} / \mathrm{H}_{2} / \mathrm{O}_{2} / \mathrm{N}_{2}$ mixture that burns to completion. Following the spark-ignited, premixed combustion, the combustion products cool over a relatively long time (700$2500 \mathrm{~ms}$ ) due to heat transfer to the vessel walls and the pressure decreases slowly. When the desired combination of pressure and temperature is reached, the fuel injector is triggered. The characteristics of the vessel and the fuel injection system are described in detail elsewhere $[18,19]$.

To relate this research to other similar works in the literature, experiments were conducted under the standardized conditions of the Engine Combustion Network, ECN [20]. Spray A represents a relatively low-temperature Diesel engine combustion relevant for engines that use a moderate rate of exhaust-gas recirculation (EGR) [39]. The fuel used in Spray A is a single-component fuel, $\mathrm{n}$-dodecane, which is known as a good surrogate for Diesel with good knowledge of its physical and chemical properties. In preceding work, Malbec et al. [19] provided a good characterization of the vessel and the injector used in the present study. To achieve the ECN targets, the same settings as shown in ref. [19] were used. A good match with ECN's database was confirmed from the lift-off length measurements via $\mathrm{OH}^{*}$ chemiluminescence for Spray A [18-20].

Best conditions for LII measurements are present in cases with locally high soot volume fractions $\left(f_{\mathrm{v}}\right)$ in a restricted area in the measurement plane but an overall low soot mass $\left(m_{\mathrm{s}}\right)$ to minimize laser attenuation and signal trapping. Among the target conditions for Diesel sprays defined by the ECN [20], 
a variant of ECN's Spray A, where the fuel is injected into a gas mixture with $21 \% \mathrm{O}_{2}$, provided the best combination of high $f_{V}$ in the center and limited $m_{s}[18]$. This is labeled as "reference condition" in this study. To investigate the effects of varying boundary conditions on the measured particle size, additional experiments were carried out where injection pressure, temperature, and $\mathrm{O}_{2}$ concentration deviated from the reference spray case (Table 1). For all these conditions, a long injection duration of $6 \mathrm{~ms}$ (longer than the Spray A standard of $1.5 \mathrm{~ms}$ ) is used to enable an analysis of the soot cloud under quasisteady conditions.

Table 1: Experimental conditions: Case 1 is the reference used in this paper, case 4 is ECN's Spray A.

\begin{tabular}{|l|c|c|c|c|}
\hline Case & $\mathrm{O}_{2} / \%$ & $\mathrm{~T} / \mathrm{K}$ & Fuel injection $p /$ bar & Fuel injection $t / \mathrm{ms}$ \\
\hline 1 (Reference) & 21 & 900 & 1500 & 6 \\
\hline 2 & 21 & 1000 & 1500 & 6 \\
\hline 3 & 21 & 900 & 1000 & 6 \\
\hline 4 (Spray A) & 15 & 900 & 1500 & 6 \\
\hline
\end{tabular}

\subsection{Optical setup}

Fig. 1 illustrates the optical arrangement of the experiment. The fuel is injected horizontally into the vessel with a Bosch injector (injector no: 201.01) [19]. For particle heating, the fundamental of a Nd:YAG laser at $1064 \mathrm{~nm}$ is used with a pulse width of $7 \mathrm{~ns}$. This wavelength is preferred to suppress interference from laser-induced fluorescence (LIF) of combustion intermediates [6]. A set of cylindrical lenses forms a horizontal laser sheet, and a $1 \mathrm{~mm}$ slit aperture crops the laser sheet into a rectangular shape that is relay-imaged into the probe volume with a pair of spherical lenses creating a nearly top-hat intensity profile. The laser sheet intersects the spray axis between 28 and $62 \mathrm{~mm}$ downstream of the nozzle. The laser is fired $3.5 \mathrm{~ms}$ after the start of injection. 


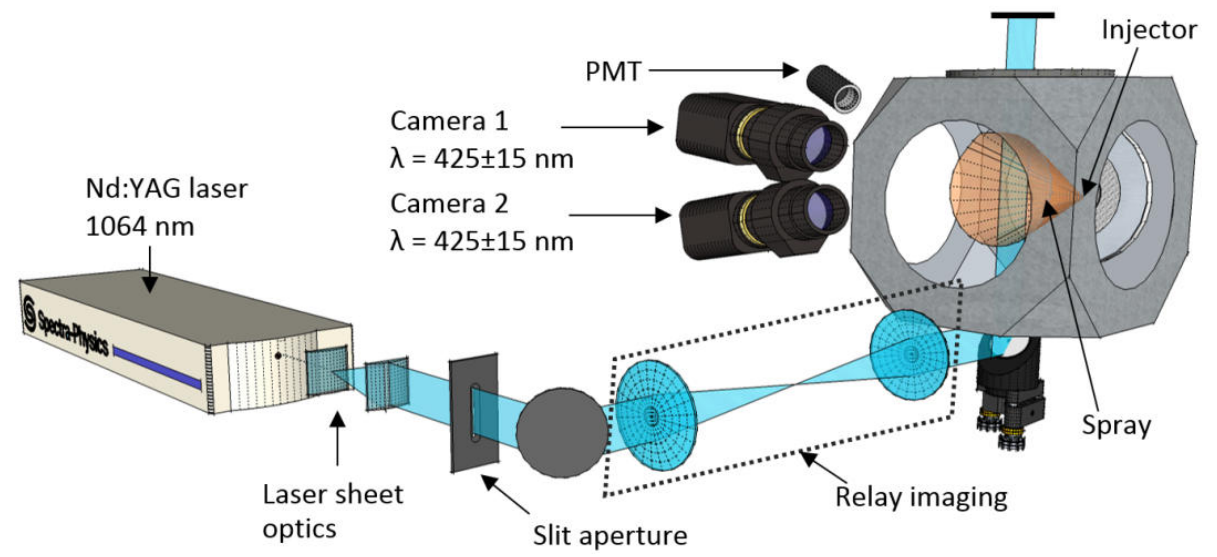

Fig. 1: Experimental arrangement.

With conventional intensified camera technology, it is not possible for a single detector to provide consecutive images within the typical LII cooling time and multiple detectors (that are in few cases combined into a single "camera" [12]) must be used. The temporal resolution of the collected data depends on the number of imaging detectors. For particle-size imaging in this work, two cameras are used. The LII signal is selected via a bandpass filter $(425 \pm 15 \mathrm{~nm})$ and imaged at near $90^{\circ}$ by $f=50 \mathrm{~mm}, f_{\#}$ $=1.4$ lenses onto the chips of an intensified CCD (camera 1, PI-MAX 2, 512×512 pixels after $2 \times 2$ binning) and an intensified EMCCD (camera 2, PI-MAX 4, 512×512 pixels). The detection wavelength of $425 \pm 15$ $\mathrm{nm}$ was found to be a good compromise between collecting sufficient signal and distinguishing the LII signal from the natural luminosity of the soot at the line of sight of the LII imaging (the temperature of the soot at the spray periphery is as high as $2500 \mathrm{~K}$ ). Based on Planck's radiation law, at a higher wavelength the relative interference of this natural soot luminosity to the LII signal would be much higher, and therefore is not preferred in this work. With the gate duration adjusted for measuring the LII signal (10 to $15 \mathrm{~ns}$ ), contributions of $\mathrm{CH}$ and $\mathrm{C}_{2}$ chemiluminescence emissions within the detection wavelength-band were negligible as their signal contribution was found to be below the dark current fluctuations of the CCD. To measure the jitter between the laser pulse and signal detection that affects the data interpretation, the LII signal is additionally detected with a fast photomultiplier (Hamamatsu R7400U-04, rise time $\sim 0.78 \mathrm{~ns}$ ) and stored together with the camera gate signals on a $1 \mathrm{GHz}$ oscilloscope.

To optimize image mapping for both cameras, three strategies were compared: 
(1) Positioning the cameras at opposite sides of the vessel was discarded because signal trapping of the randomly-oriented soot cloud significantly affected both images individually and thus influence the signal ratio.

(2) Observing the probe volume with both cameras from one side via a $50 \%$ beam splitter provided a perfect geometric overlap that minimizes the influence of signal trapping on the intensity ratio but the $50 \%$ signal loss resulted in an unwanted deterioration of the signal-to-noise ratio.

(3) As the best compromise, both cameras were positioned next to each other detecting signal through the same window but at slightly different angles (Fig. 1). For mapping of the slightly distorted images a strategy developed by Tea et al. [40] was used.

Based on the numerical analysis performed in ref. [14], a combination of detection gates was chosen, one starting at the signal peak and the other with a 5 ns delay. For condition 1, 3, and 4 (cf. Table 1), the gate width of both cameras was set to $15 \mathrm{~ns}$, whereas a 10-ns gate was sufficient for condition 2 with a larger $f_{\mathrm{V}}$.

For two-color pyrometry, spectral bands were selected according to the recommendation of [31] and the bandpass filter of camera 1 was replaced with a $676 \pm 15-\mathrm{nm}$ filter while the filter of camera 2 was kept. The relative sensitivity of both detectors was calibrated against the well-documented temperature of a non-premixed ethylene/air Santoro flame [41] operated under standard conditions $\left(\mathrm{C}_{2} \mathrm{H}_{4}: 0.232\right.$ standard liters per minute, slm, air co-flow: $43 \mathrm{~s} / \mathrm{m}$ ). Because this calibration is based on soot emission, the emissivity ratio in the pyrometry equation [15] is identical in calibration and the actual measurements (assuming that emissivity does not change with soot temperature and morphology). Pyrometry imaging was used to determine LII heat-up temperatures where both cameras were activated at the LII signal peak with 15-ns gate times.

\subsection{Ex-situ soot analysis}

Soot was sampled from various locations of the soot cloud by thermophoretic deposition on a carboncoated copper grid that stays in a steel grid-holder probe that is attached to the side wall opposite to the injector at variable distance from the injector. This setup was reproduced from ref. [42]. An image of the sampling device and $3 \mathrm{~mm}$ diameter carbon coated copper grid is shown in Fig. 2a. A Schlieren imaging measurement of the flame with the inserted sampling device is shown in Fig. $2 b$ (injector is at the left side wall). 


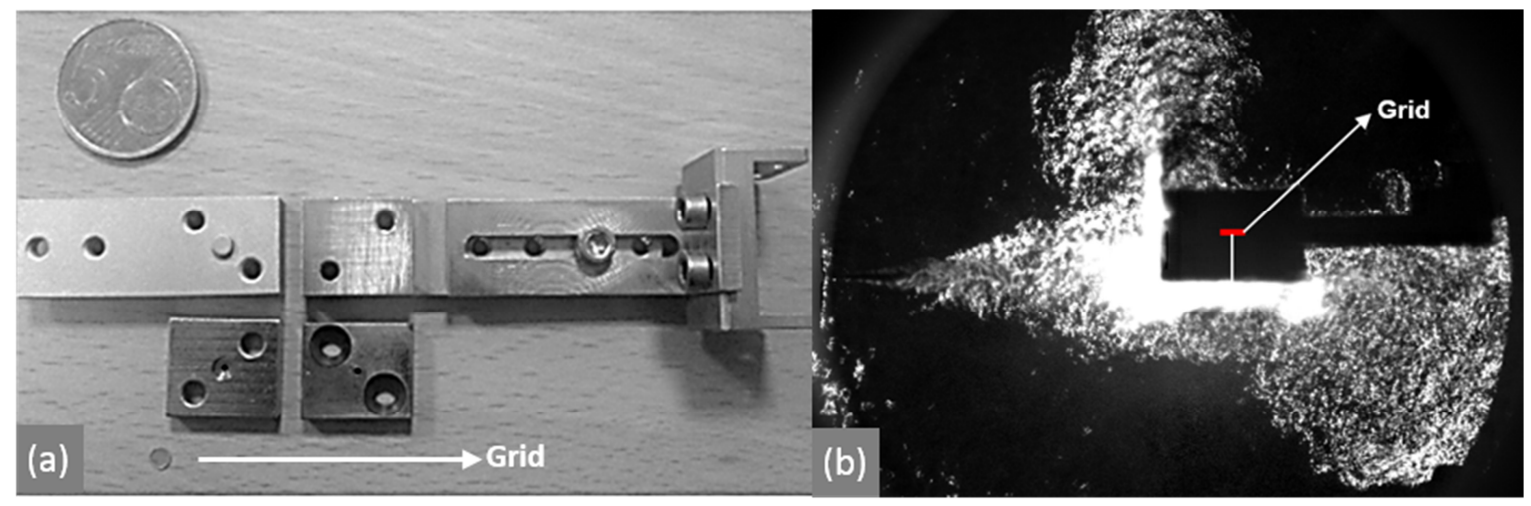

Fig. 2: (a) Upper and lower jaws, telescopic extension unit, and carbon-coated copper grid of the sampling device. (b) Schlieren image of the flame with the inserted sampling device. The steel gridholder probe for soot sampling is attached to the side wall of the vessel opposite to the injector. The upper half of the jet impinges onto the probe but the lower half of the spray is relatively undisturbed. With a telescopic design, the grid can be positioned at variable distance from the injector.

The probe is placed slightly above the main jet flow axis (upper half of the jet impinges onto the probe but the lower half of the spray is undisturbed) to minimize flow disturbance as shown with the Schlieren image. The particle-laden flow enters the probe through a 1-mm diameter hole and soot particles are deposited on the grid. The restricted flow passage ensures flame quenching and also protects the grid against excessive heating [42,43]. The sampling location (position of the hole) was chosen as the position of maximum soot emission along the spray axis as determined for each condition from soot luminosity images. For the four cases of Table 1, these locations were 45, 42, 41, and $60 \mathrm{~mm}$ downstream of the injector orifice. For case 1, additional samples were extracted at 36 and $60 \mathrm{~mm}$ to investigate zones of soot formation and burn-out. In a recent study, Kondo et al. [44] performed sampling while positioning the grid at different angles from 0 to 90 degrees to the flow, and they concluded that the amount of sampled soot is independent of the angle of the grid to the flow. To prevent cross-contamination, the probe and the high precision tweezers used for handling the TEM grids were cleaned with ethanol in an ultrasonic bath in between experiments.

The samples were investigated by high-resolution transmission electron microscopy (HR-TEM: JEM$2100 \mathrm{~F}$, operating voltage: $200 \mathrm{keV}$, point resolution: $0.19 \mathrm{~nm}$ ) equipped with a CCD camera at the School of Science and Technology, Meiji University, Japan. The TEM grids were investigated without any thermal or chemical pre-treatment to maintain the properties of the soot particles sampled in Diesel flames as much as possible. Details of sample treatment and analysis are described in section 4.3 and in 
ref. [43]. More than five TEM images were taken at five different locations on each TEM grid with clear distance with a magnification of $\times 20,000$ or $\times 40,000$. The time between the sampling and the TEM investigation was slightly longer than one month. Aizawa et al. [43] reported that the delay has no impact on the measurements. Ex situ characterization of soot is inherently subjected to an uncertainty as the particle sizing is an operator dependent work. Various related uncertainty sources are discussed in ref. $[24,45]$.

\section{Results}

\subsection{Pyrometry imaging}

The particle heat-up temperature depends on the local laser fluence, the optical properties of soot, the surrounding gas temperature, and heat transfer with the environment. Heat-up temperature should be high enough to provide strong signals while avoiding particle evaporation.

Across the measurement plane the local laser fluence can vary due to an imperfect laser profile and laser attenuation. Additionally, the absorption properties of soot can change during aging of soot. The gas temperature is mostly related to the mixture fraction and thus typically varies within the measurement domain. The combined effects can lead to a non-uniform distribution in particle heat-up temperatures that was investigated by two-color pyrometry imaging. The temperature was derived for each pixel from the ratio of signal intensities within two detection bands. As discussed above, heat transfer during the laser pulse causes an inhomogeneous temperature distribution within the polydisperse particle ensemble with pyrometry preferentially measuring the high-temperature end of the distribution. Furthermore, the lifetime of the LII signal is only marginally longer than the gate duration required for the collection of sufficiently strong signal. Therefore, an instantaneous measurement of the peak particle temperature cannot be achieved and the actual results are biased towards lower temperatures because significant cooling of the particles during the measurement interval. Our model-based analysis [14] leads to an estimated bias for our conditions of $\sim 200 \mathrm{~K}$. The magnitude of this bias is directly related to the cooling rate of the particles during the gate width of camera acquisition and must be evaluated for each system or experiment conditions. A correction of the systematic error in the temperature measurements due to the signal trapping is omitted in this work as the optical thickness in the target flame [18] is usually smaller than what Schraml et al. [32] measured 
(cf. section 2). However the evaluated temperature can be non-negligibly biased to lower temperatures in spray events where strong local soot volume fractions occur.

The best-suited laser fluence for our experiments was chosen based on the measured heat-up temperatures as a function of laser fluences (varied by changing the Q-switch delay of the Nd:YAG laser). At each laser fluence, 15 experiments were conducted and an ensemble average was calculated. Each data point in Fig. 3 represents a mean value determined in a $2 \times 2$-pixel square at the maximum value found in the ensemble-averaged images (increased by $200 \mathrm{~K}$ according to the discussion above). The error bars represent the spatially-averaged pixelwise-recorded standard deviation in temperature, based on shot-to-shot variations. To suppress the influence of background signal, i.e., line-of-sight integrated flame luminosity, 20 experiments without laser heating were taken under identical conditions and the ensemble-averaged signals were subtracted from the respective channels. Furthermore, due to the large temperature difference between the heated soot zone and the non-heated soot in the line of sight, the contribution of blackbody-like radiation from the non-heated soot to the overall signal is only marginal. Musculus et al. [46] showed that the possible bias towards lower temperature in soot pyrometry due to such gradient effect is negligible in Diesel engine conditions. The phase-averaged background intensity (no laser, only soot luminosity) at maximum soot volume fraction zone is around $8 \%$ of the LII signal intensity at the same location from a single-shot LII image. The pixel-to-pixel variation in the measurement domain of the ensemble-averaged image was $6 \%$ of the mean showing that the temperature distribution was fairly homogeneous. The maximum laser fluence in our experiment was $0.2 \mathrm{~J} / \mathrm{cm}^{2}$ which is not sufficient at 60 bar to reach the maximum particle temperature limited by sublimation. For all particle-sizing measurements, the laser fluence was set to $\sim 0.15 \mathrm{~J} / \mathrm{cm}^{2}$ because this yielded sufficient signal with limited evaporation. Note that similar laser fluences cause noticeably higher peak temperatures at atmospheric pressure.

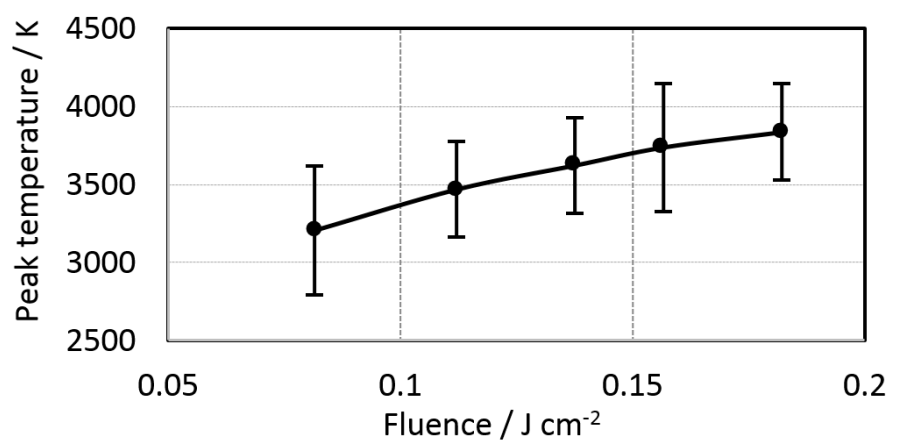


Fig. 3: Effect of laser fluence on peak temperature. Vertical bars represent the standard deviation of the ensemble average, based on variations between individual experiments.

To determine the bath-gas temperature within the laser sheet in the center of the jet, mixturedependent adiabatic flame temperatures were calculated using a simple fuel/air-entrainment model [47] and CHEMKIN tool for constant volume conditions. The injector geometry information relevant for this model were imported from ref. [48]. We additionally used the CFD results of a similar spray [49]. These models yield a temporally-averaged temperature distribution, and therefore do not reflect instantaneous variations. Both approaches showed that the gas temperature along the jet axis increases with increasing distance from the orifice.

\subsection{Particle-size imaging}

To correctly evaluate the measured LII signal ratios, information about local conditions (temperature, gas composition, pressure, optical properties of soot, morphology) are necessary for modeling the heating and cooling processes. Because these spatially and temporally varying conditions are not known, a phenomenological approach is used assuming homogeneous conditions for any measurement instant (cf. Table 2) where conditions are only modified in case reliable information about the expected variation exists. The pressure was measured for each experiment and the standard deviation from 950 experiments was less than $0.6 \%$ of the target value. Therefore, for all measurements in case 1,3 , and 4 (Table 1), an ambient pressure of 61 bar was used, whereas in case 2, this value was 68 bar. For temperatures, based on the simulations mentioned above, the measurement domain ( $x=28-62 \mathrm{~mm}$ ) was divided into nine equal segments with $50 \mathrm{~K}$ increments from 1600 to $2000 \mathrm{~K}$ while assuming invariant temperatures along the radial direction. For each segment a unique LII model-library was created.

Table 2: Boundary conditions for particle sizing in the reference case.

\begin{tabular}{|l|c|}
\hline \multicolumn{2}{|c|}{ LII model input } \\
\hline Ambient pressure & $61 \mathrm{bar}$ \\
\hline Detection range & $410-440 \mathrm{~nm}$ \\
\hline Gas temperature & $1600-2000 \mathrm{~K}$ \\
\hline Laser fluence & $0.15 \mathrm{~J} / \mathrm{cm}^{2}$ \\
\hline Laser pulse duration & $7 \mathrm{~ns}$ \\
\hline$E(m)$ & 0.4 \\
\hline Aggregate size & 50 \\
\hline
\end{tabular}


\begin{tabular}{|l|l|}
\hline Thermal accommodation coefficient & 0.25 \\
\hline
\end{tabular}

Because the measurements of the heat-up temperatures did not show significant spatial variations, absorption-related parameters, i.e., laser fluence, laser pulse duration and absorption properties $(E(m)=$ 0.4 [2]) were kept fixed for all the pixels in all the simulations. The heat-up temperatures predicted by the model were compared to the pyrometric measurements and it was found that it was within the uncertainty range. For the thermal accommodation coefficient, $\alpha_{\mathrm{T}}$, a constant value of 0.25 was used for all the simulations $[7,50]$. Based on a statistical analysis of previous TEM measurements of soot morphology for comparable conditions [43], an aggregate size of 50 is chosen for all simulations assuming the properties of graphite-like material [51]. For heat conduction, Fuchs' approach was chosen in LIISim and calculations were done for mono-disperse soot. Particle-size imaging based on time-gated signal ratios is inherently based on a mono-disperse assumption because the necessary information for a more detailed analysis is lost during the integration of the LII signal and gate delaying. The measured actual gate times relative to the laser pulse were used to create virtual gated signals in the modeling. Gate timings were measured on a fast oscilloscope directly from the monitor outputs of the cameras. The camera manufacturer provides the jitter uncertainty as $35 \mathrm{ps}$ rms. The gate profiles were assumed to be rectangular.

The standard procedure of two time-step imaging is shown in Fig. 4. The LII signals are recorded with two cameras from in a single spray event with a $5 \mathrm{~ns}$ delay in-between. After pixel mapping of the images and normalization of signals for camera gain settings, the ratio of two images (delayed signal over the first signal). Then each pixel in the ratio map is converted into particle size by using the libraries of LII signals simulated for specific local conditions. Particle sizes out of $0-50 \mathrm{~nm}$ interval are discarded on the output image. The gate timings and laser timing are monitored on a scatter plot read out from the oscilloscope. 


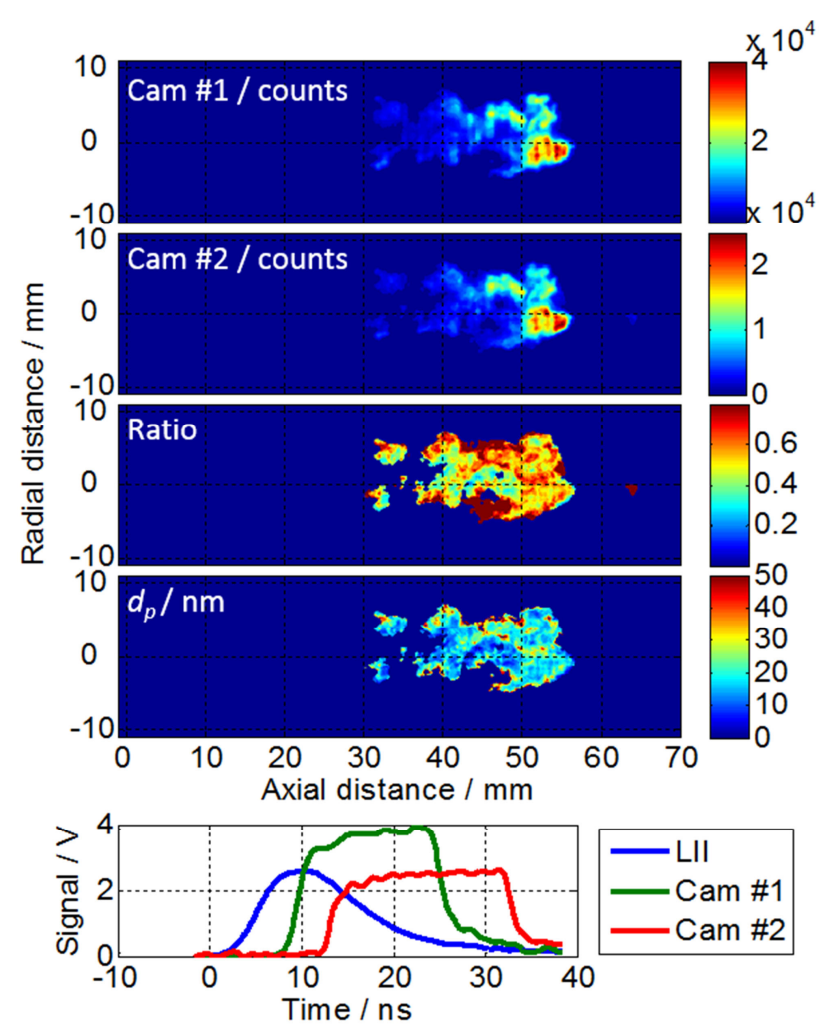

Fig. 4 Two time-step LII imaging. The first two images from the top show single shot LII images taken by the first (Cam \#1) and the delayed camera (Cam \#2). Each image has its own colormapping and shown with the colorbars on the right hand side. The third image shows the ratio of the two LII images (Cam \#2 over Cam \#1) taken after the pixel mapping and camera gain corrections. The fourth image shows the particle size distribution. Each pixel in the ratio map above is converted into particle size by using the libraries of LII signals simulated for specific local conditions. The scatter plot at the bottom is exported from the oscilloscope. The LII signal is measured with a PMT at the region of interest. The gate timings are acquired directly from the monitor outputs of the cameras. The information in this plot is used for jitter corrections.

Fig. 5 shows evaluated particle sizes for four conditions (cf. Table 1) as ensemble averages of 20 measurements. Areas with pixel values below $5 \%$ of the maximum intensity in each image were discarded when determining the ratio. Strong cyclic variations were observed in the particle-size images at all conditions. In case 4, soot oxidation takes over formation at a further distance than the measurement domain. The sharp cut at $x=62 \mathrm{~mm}$ is actually due to the end of laser-illuminated zone.

In Fig. 6, the ratio of the standard deviation calculated from 20 experiments to the ensemble mean is shown for the reference condition. The spatially-averaged value of the relative standard deviation is 
$40 \%$. These variations can be related to the turbulent nature of the Diesel combustion process. Furthermore, the actual deviations in the assumed boundary conditions for size evaluation can cause different results in each individual experiment.

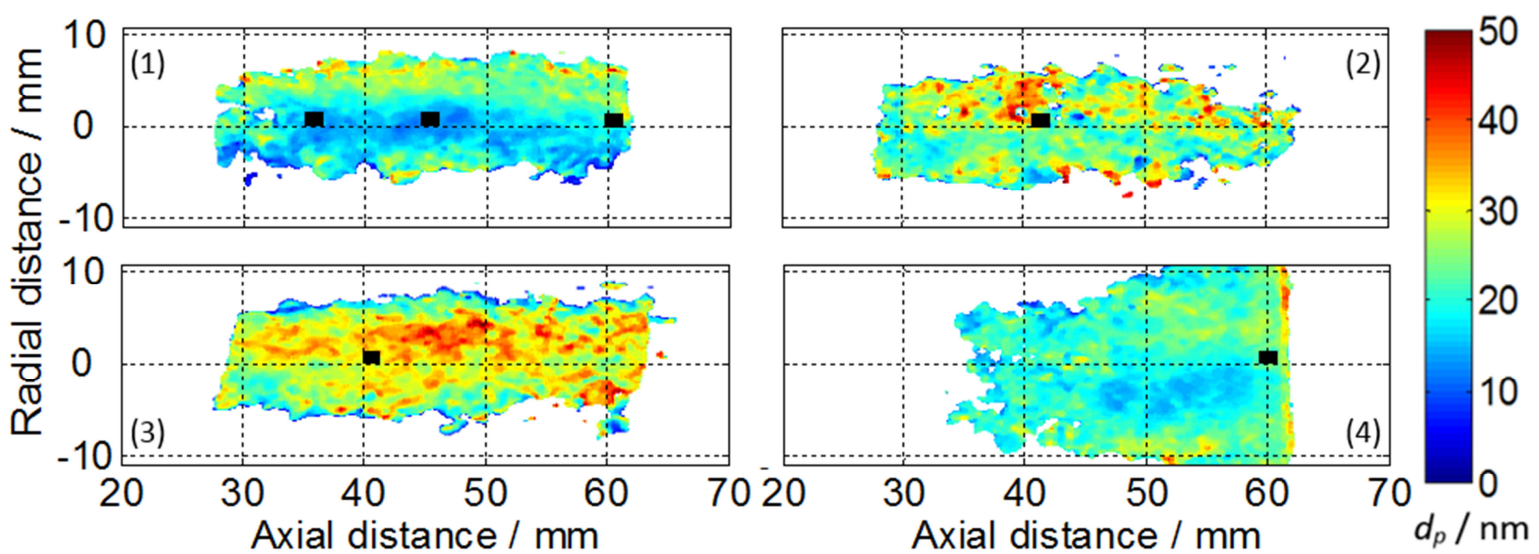

Fig. 5: Spatially-resolved particle-size distributions from LII for cases 1-4 in Table 1. Sampling locations are shown with black rectangles.

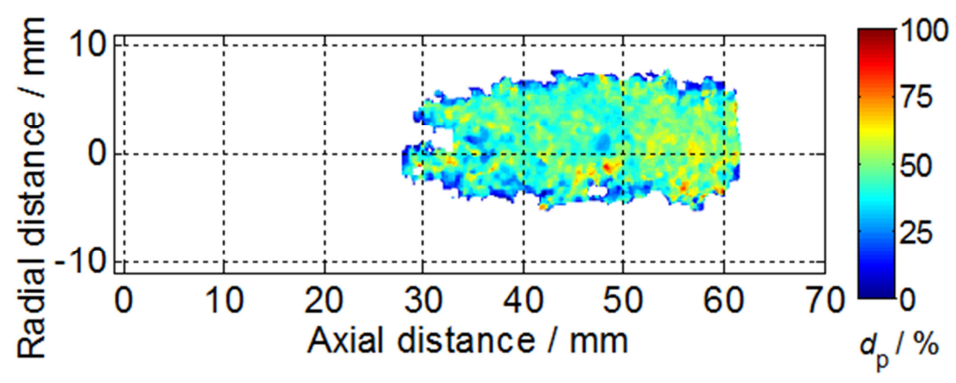

Fig. 6: Cyclic variations: Relative standard deviation (in percent) from 20 individual measurements at the reference spray conditions.

\subsection{Electron microscopy results}

The particle size was additionally determined from TEM micrographs acquired from soot sampled in the reference spray at three different axial locations. Primary particle diameters are determined manually from the micrographs. The structure of the soot aggregate has been determined from the projected TEM images only. Software developed at the Combustion Research Facilities of Sandia National 
Laboratories and revised at Meiji University is used in this analysis [43]. Here primary particles that can be identified within aggregates as well as separately existing single primary particles were measured. It has been confirmed that the particle-size distribution and the mean value is not biased by this selective sampling of identifiable primary particles [52]. For all particles the diameter was determined from two (perpendicular) directions and the average value of both was used to account for non-circular shapes.

In each zone with increasing $f_{\mathrm{V}}(x=36$ and $45 \mathrm{~mm})$, the size of 650 particles was evaluated. In the oxidation zone $(x=60 \mathrm{~mm})$ only 272 particles could be measured due to the sparse soot deposition on the grid. In Fig. 7 three sample micrographs are shown each acquired at a different location. Note that first micrograph has a different scaling than the other two.
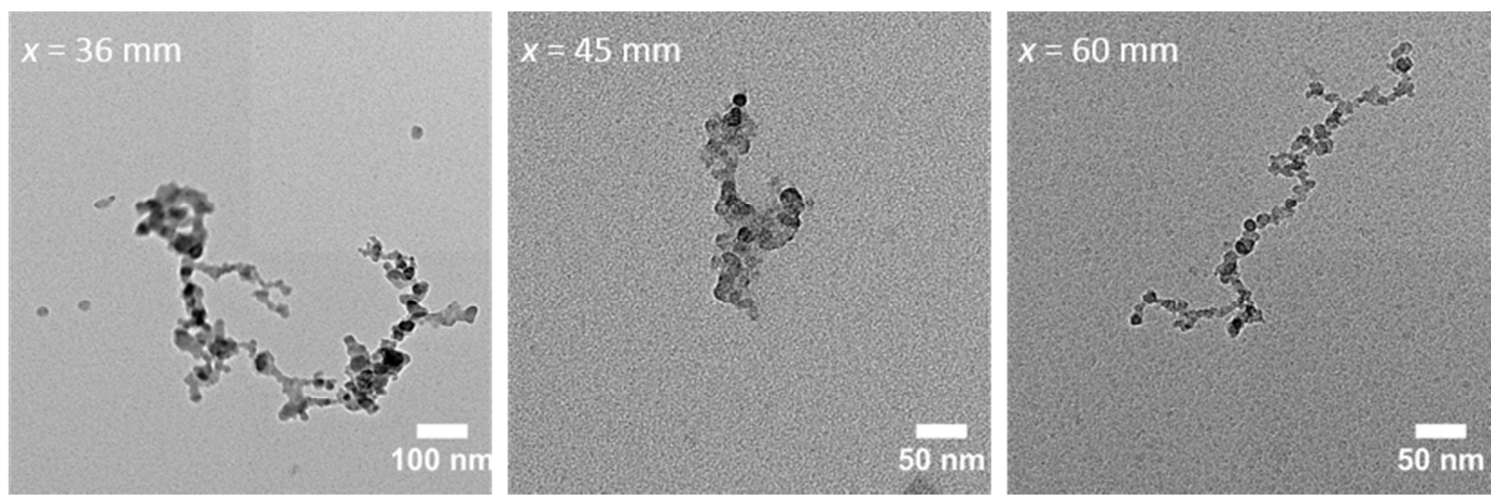

Fig. 7: TEM micrographs acquired from soot sampled in the reference spray at three different axial locations. Scales bars specific to each micrograph are shown at the lower right corner.

Fig. 8 shows the normalized size distributions from the TEM analysis. Fitting a log-normal distribution to each of the curves revealed count median diameters $\left(d_{\mathrm{cmd}}\right)$ of $14.7,9.9$, and $7.3 \mathrm{~nm}$ at $x=36,45$, and 60 $\mathrm{mm}$, respectively. In contrast, LII obtained arithmetic mean values of 13.7, 13.3, and $19.6 \mathrm{~nm}$ for the same areas, respectively, as determined from a $1-\mathrm{mm}^{2}$ field on the centerline of the ensemble-averaged images. These results derived by LII are shown as vertical bars in Fig. 8. Fig. 9 shows the TEM-derived normalized size distributions for soot sampled at each experimental condition given in Table 1 . The number of particles measured at each condition is 660, 950,660, and 1000 and the measured count median diameters are 9.9, 13.1, 9.1, and $9.1 \mathrm{~nm}$ for case 1 to 4 , respectively. The particle sizes derived from LII imaging are shown as vertical lines in Fig. 9 with arithmetic mean values of 13.3, 24.2, 32.1, and $20.2 \mathrm{~nm}$, respectively. 


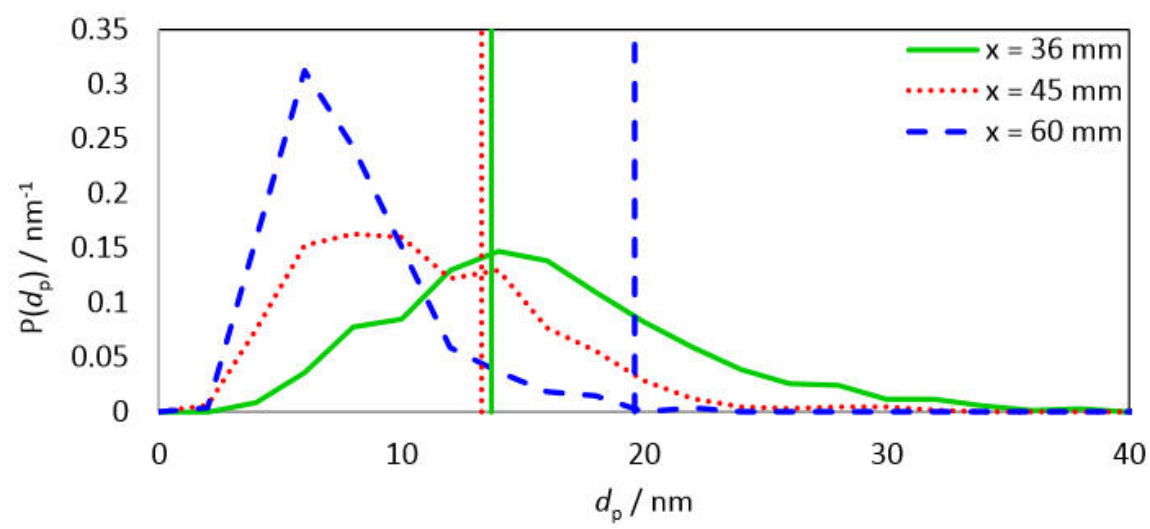

Fig. 8: Particle-size histograms from TEM analysis of soot sampled at three locations along the spray axis for case 1 (Table 1). The size distributions are normalized and the integral of distribution curve is equal to unity. Vertical lines represent the spatially-averaged particle sizes from LII for the respective axial positions.

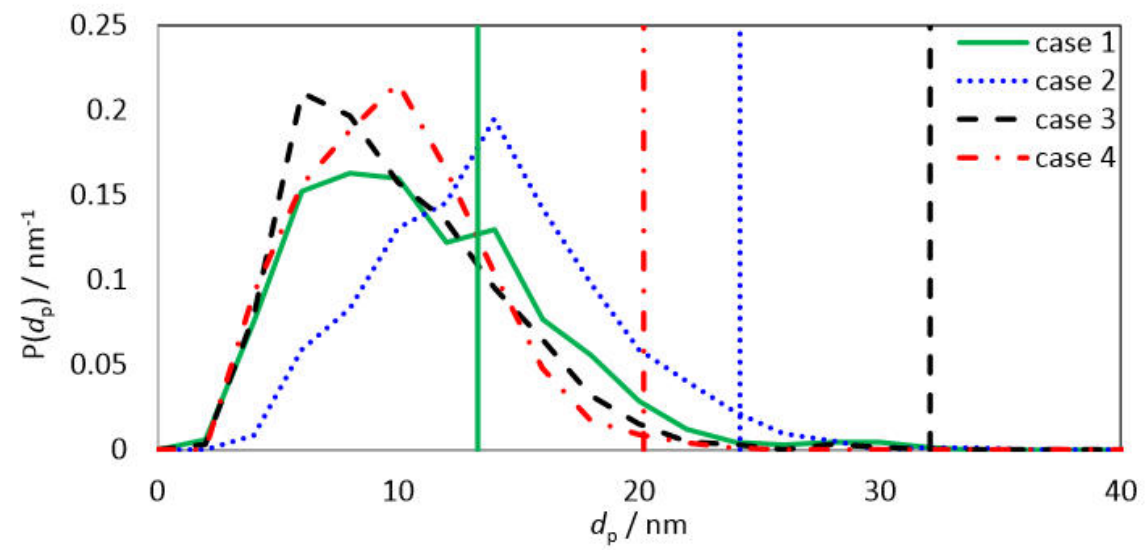

Fig. 9: Particle-size histograms from TEM analysis of soot sampled at the position of maximum soot emission along the spray axis for cases 1-4 in Table 1. The size distributions are normalized and the integral of distribution curve is equal to unity. Vertical lines represent the spatially-averaged particlesizes from LII for the respective location and conditions.

\section{Discussion}

The particle sizes determined from LII and TEM determined in the measurements presented above show substantial differences. Both measurements contain several sources of uncertainty. One major problem of LII particle sizing at high pressures relevant for Diesel combustion is related to the fact that small 
particles are generally underrepresented in the measured signal intensity. TEM measurements from the present study and comparable situations $[42,52]$ show that the mean primary particle size is $\sim 15 \mathrm{~nm}$. With such small particles the LII-signal lifetime is too short for adequately capturing the signal contribution of these particles by the delayed-gate technique applied here. Furthermore, the polydisperse nature of the soot and the strong dependence of the LII signal on particle size cause a strong bias towards the larger particles in the ensemble.

To better understand the discrepancy between the LII-derived and the TEM-derived particle sizes, a numerical analysis is performed with the Diesel jet measurement results: A phantom LII signal of a polydisperse soot cloud is simulated using the actual particle-size distribution derived from the TEM analysis of the reference spray at $x=45 \mathrm{~mm}$, and the particle size is evaluated by forming a signal ratio on this simulated LII trace. The gated LII signal ratio method yields a mono-disperse equivalent mean particle size of $21.5 \mathrm{~nm}$, whereas the $d_{\mathrm{cmd}}$ of the size distribution evaluated from the TEM measurements was $9.9 \mathrm{~nm}$. This result shows that the LII bias towards larger particles more than doubles the measured particle-size compared to the mean size in the distribution determined from TEM for the present conditions (the bias towards larger particle sizes at high pressure is larger than at atmospheric conditions). In the ensemble-averaged particle size distribution images (cf., Fig. 5), a systematic variation of the particle size along the jet axis related to soot formation and oxidation could not be seen. This result is in contrast to previous $f_{v}$ measurements in the same spray (cf., ref. [18]) and to the TEM results. The reason of such uniformity across the imaged spatial domain can again be attributed to the bias towards larger particles in the LII method. At each local zone only the largest particles contribute to the measurement and information from the smaller particles is lost. Furthermore, ensemble averaging of 20 measurements is not adequate to capture the systematic changes in particle size along the propagation direction of the reacting spray. The slight variation in particle size in radial direction is believed to be caused mainly by errors due to imperfect image mapping.

Additional uncertainty in LII particle sizing is caused by the assumptions made for the local bath gas conditions because detailed knowledge of the instantaneous and local conditions is not available. For soot morphology related properties, i.e., $E(m), \alpha_{\mathrm{T}}$, and aggregate size, the input parameters can spatially vary. Small variations in all these parameters may have substantial effects on the evaluated particle sizes. When changing the assumed bath gas temperature from 1600 to $2000 \mathrm{~K}$ at a given location in the reference case, the evaluated mean particle size is reduced by $25 \%$. This is due to the fact that with increasing gas temperature at Table 2 conditions in the simulations, the overall heat 
conduction rate decreases due to a reduced temperature difference between heated particles and the bath gas. Therefore, smaller particle sizes are evaluated to compensate the reduced LII signal decay rate when higher gas temperatures are assumed. To measure the magnitude of these uncertainties on the results as shown in ref. [14], the uncertainties in the modeling parameters, for instance in the form of some confidence intervals, should be known. While this can be achieved for some of these parameters, it is not possible to measure certain parameters such as thermal heat accommodation coefficient or absorption function. In this work, such kind of uncertainty quantification is not performed. Additional uncertainties should be considered in imaging applications due to shot noise [14], deviation of the gate profiles from the assumed top-hat profile, and imperfect image mapping.

One important aspect in the present study is the correction for the jitter that can occur in the delay between laser pulse and signal detection. To quantify the error when neglecting jitter, the size evaluation is performed with a first gate fixed to the peak signal and a second gate with a fixed $5 \mathrm{~ns}$ delay in the model library. This changed the evaluated spatially-averaged particle size by more than $20 \%$, whereas the deviation at some local pixels was up to $50 \%$. The ensemble-averaged distribution of the particle-size variation due to the timing jitter is shown in Fig. 10. The jitter correction is effective only if heat-up modeling is included in the signal library.

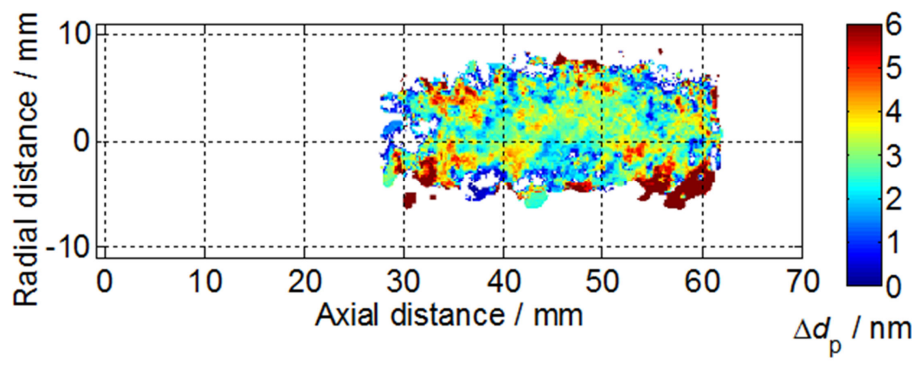

Fig. 10: Variation of particle sizes evaluated without consideration of the actual timing jitter in the system.

It must, however, be considered that uncertainties also exist in TEM measurements where the probe can interfere with the dynamics and combustion of the Diesel jet and the deposited soot on the grids can further oxidize leading to sizes smaller than expected. It is a challenge to probe soot from a highly dynamic Diesel spray cloud and the arrangement used here clearly affects the flame development and hence soot. Additional operator-biased errors can occur in the analysis of the micrographs [45]. In this study the amount of soot deposited on the TEM grid was very limited leading to a small number of analyzed particles. A quantitative analysis of these uncertainties was not possible in these 
measurements. However, the evaluation of the bias towards larger particles for LII shows that in Diesel engine conditions, due to the small size of the particles and the high pressure, particle-size measurements with LII contain major uncertainties and - besides all limitations - soot sampling with subsequent TEM analysis provides valuable complementary results. However, because TEM sampling does not provide spatial information and can strongly influence the Diesel jet, the imaging capabilities of the LII technique are considered beneficial even if a quantification of the results is not possible.

\section{Conclusions}

Two-dimensional particle-size imaging with laser-induced incandescence was performed in a highpressure Diesel combustion vessel. The main purpose of the study was to assess the practical utilization of the two time-step LII imaging method experimentally for the high-pressure conditions, and to optimize its performance. An additional purpose was to investigate effects of varying spray conditions on the evaluated soot particle-size and its spatial distribution. The experiments were conducted under the well-defined conditions of ECN's Spray A and its parametric variants to benefit from accumulated previous information and to further contribute to the database. The method in this work was based on simulations of the signal ratio from two gated portions of the LII signal trace acquired at different timings and using LII modeling to deduce the local particle size from the measured signal ratio. To verify the optimum laser fluence soot heat-up temperatures were measured via two-color pyrometry imaging. The heat-up temperature necessary for modeling the LII signal trace is automatically calculated from the absorption model. To correct for temporal jitter in the experimental gate timing, a fast photodiode and oscilloscope recorded the LII signal event and camera gates simultaneously with the imaging system, and necessary time corrections were made in the modeling. For ex situ characterization, soot particles were sampled at multiple axial locations. Particle-size distributions were derived from TEM measurements and compared to the LII results. Substantial discrepancies were observed between results from both methods.

The strong non-linear dependence of the LII intensity on particle size and temperature causes a strong bias towards information from larger particles in the acquired signal. In this study, it can be seen that this bias is severe for high-pressure conditions because the small particles quickly loose energy already during the laser heat-up leading to lower peak temperatures and also cool down quickly afterwards. The combined effect makes them almost invisible during the LII decay with conventional nanosecond laser and detector equipment. An additional source of uncertainty arises from that fact that spatially- and 
temporally-resolved information about bath gas conditions and materials properties is not available. Due to the combined effects, a quantitative particle-size analysis with LII imaging could not be accomplished at the $>60$ bar conditions of the present experiments.

\section{Acknowledgements}

The authors thank Clement Bramoulle at IFPEN for experimental assistance. The authors are grateful to Hideyuki Yoshimura of Department of Physics, Meiji University for providing the TEM. The authors also thank Kei Okabe, Kota Suzuki, Hiroyuki Takano, Junya Takahashi, and Yuki Hattori for their assistance in TEM analysis. Thomas Dreier and Christof Schulz acknowledge support from the German Science Foundation, DFG, through SCHU1369/3.

\section{References}

[1] International council on clean transportation, Pocketbook: European Vehicle Market Statistics, Berlin, 2013.

[2] D.R. Snelling, G.J. Smallwood, F. Liu, Ö.L. Gülder, W.D. Bachalo, Appl. Opt. 44 (2005) 6773-6785.

[3] J.C. Chow, J.G. Watson, J.L. Mauderly, D.L. Costa, R.E. Wyzga, S. Vedal, G.M. Hidy, S.L. Altshuler, D. Marrack, J.M. Heuss, G.T. Wolff, C. Arden Pope III, D.W. Dockery, J. Air Waste Manage. Assoc. 56 (2006) 1368-1380.

[4] V. Ramanathan, G. Carmichael, Nat. Geosci. 4 (2008) 221-227.

[5] L.A. Melton, Appl. Opt. 23 (1984) 2201-2208.

[6] C. Schulz, B.F. Kock, M. Hofmann, H.A. Michelsen, S. Will, B. Bougie, R. Suntz, G.J. Smallwood, Appl. Phys. B 83 (2006) 333-354.

[7] H.A. Michelsen, F. Liu, B.F. Kock, H. Bladh, A. Boiarciuc, M. Charwath, T. Dreier, R. Hadef, M. Hofmann, J. Reimann, S. Will, P.-E. Bengtsson, H. Bockhorn, F. Foucher, K.-P. Geigle, C. MounaïmRousselle, C. Schulz, R. Stirn, B. Tribalet, R. Suntz, Appl. Phys. B 87 (2007) 503-521. 
[8] B.F. Kock, T. Eckhardt, P. Roth, Proc. Combust. Inst. 29 (2002) 2775-2782.

[9] S. Will, S. Schraml, A. Leipertz, Proc. Combust. Inst. 26 (1996) 2277-2284.

[10] B. Axelsson, R. Collin, P.-E. Bengtsson, Appl. Phys. B 72 (2001) 367-372.

[11] B.C. Connelly, Quantitative Characterization of Steady and Time-Varying, Sooting, Laminar Diffusion Flames Using Optical Techniques, PhD thesis, Yale University, 2009.

[12] Z. Sun, D.H. Gu, G.J. Nathan, Z.T. Alwahabi, B.B. Dally, Proc. Combust. Inst. 35 (2015) 3673-3680.

[13] J. Reimann, S.-A. Kuhlmann, S. Will, Appl. Phys. B 96 (2009) 583-592.

[14] E. Cenker, G. Bruneaux, T. Dreier, C. Schulz, Appl. Phys. B accepted (2015) DOI: 10.1007/s00340015-6009-0.

[15] M. Hofmann, B.F. Kock, T. Dreier, H. Jander, C. Schulz, Appl. Phys. B 90 (2007) 629-639.

[16] M. Hofmann, B.F. Kock, C. Schulz, in:, Eur. Combust. Meet., European Combustion Meeting 2007, Chania, 2007.

[17] L.M. Pickett, C.L. Genzale, G. Bruneaux, L.M. Malbec, L. Hermant, C. Christiansen, J. Schramm, SAE Int. J. Engines 3 (2010) 156-181.

[18] E. Cenker, G. Bruneaux, L.M. Pickett, C. Schulz, SAE Int. J. Engines 6 (2013) 352-365.

[19] L.M. Malbec, J. Egúsquiza, G. Bruneaux, M. Meijer, SAE Int. J. Engines 6 (2013) 1642-1660.

[20] L.M. Pickett, available at <http://www.sandia.gov/ecn/index.php>.

[21] M. Hofmann, W.G. Bessler, C. Schulz, H. Jander, Appl. Opt. 42 (2003) 2052-2062.

[22] H.A. Michelsen, J. Chem. Phys. 118 (2003) 7012-7045.

[23] H. Bladh, J. Johnsson, N.-E. Olofsson, A. Bohlin, P.-E. Bengtsson, Proc. Combust. Inst. 33 (2011) 641-648. 
[24] E. Cenker, G. Bruneaux, T. Dreier, C. Schulz, Appl. Phys. B 118 (2015) 169-183.

[25] B. Mewes, J.M. Seitzman, Appl. Opt. 36 (1997) 709-717.

[26] B.B. Collier, M.J. McShane, Anal. Chem. 84 (2012) 4725-31.

[27] A. Ehn, O. Johansson, A. Arvidsson, M. Aldén, J. Bood, Opt. Express 20 (2012) 3043-56.

[28] H.C. Hottel, F.P. Broughton, Ind. Eng. Chem. 4 (1932) 166-174.

[29] Y.A. Levendis, K.R. Estrada, H.C. Hottel, Rev. Sci. Instrum. 63 (1992) 3608-3621.

[30] H. Zhao, N. Ladommatos, Prog. Energy Combust. Sci. 24 (1998) 221-255.

[31] F. Liu, D.R. Snelling, K.A. Thomson, G.J. Smallwood, Appl. Phys. B 96 (2009) 623-636.

[32] S. Schraml, S. Dankers, K. Bader, S. Will, A. Leipertz, Combust. Flame 120 (2000) 439-450.

[33] D.R. Snelling, F. Liu, G.J. Smallwood, Ö.L. Gülder, Combust. Flame 136 (2004) 180-190.

[34] B. Bougie, L.C. Ganippa, a. P. van Vliet, W.L. Meerts, N.J. Dam, J.J. ter Meulen, Proc. Combust. Inst. 31 (2007) 685-691.

[35] B. Bougie, L.C. Ganippa, N.J. Dam, J.J. ter Meulen, Appl. Phys. B 83 (2006) 477-485.

[36] T. Dreier, B. Bougie, N. Dam, T. Gerber, Appl. Phys. B 83 (2006) 403-411.

[37] M. Charwath, R. Suntz, H. Bockhorn, Appl. Phys. B 104 (2011) 427-438.

[38] H.A. Michelsen, Appl. Phys. B 83 (2006) 443-448.

[39] M. Meijer, B. Somers, J. Johnson, J. Naber, S.-Y. Lee, L.-M. Malbec, G. Bruneaux, L.M. Pickett, M. Bardi, R. Payri, T. Bazyn, At. Sprays 22 (2012) 777-806.

[40] G. Tea, G. Bruneaux, J.T. Kashdan, C. Schulz, Proc. Combust. Inst. 33 (2011) 783-790.

[41] R.J. Santoro, H.G. Semerjian, R.A. Dobbins, Combust. Flame 51 (1983) 203-218. 
[42] S. Kook, L.M. Pickett, Proc. Combust. Inst. 33 (2011) 2911-2918.

[43] T. Aizawa, H. Nishigai, K. Kondo, T. Yamaguchi, J.-G. Nerva, C. Genzale, S. Kook, L.M. Pickett, SAE Int. J. Fuels Lubr. 5 (2012) 665-673.

[44] K. Kondo, J. Takahashi, T. Aizawa, SAE Int. J. Fuels Lubr. 7 (2014) 2014-01-2637.

[45] K. Kondo, T. Aizawa, S. Kook, L.M. Pickett, SAE Tech. Pap. (2013) 2013-01-0908.

[46] M.P.B. Musculus, S. Singh, R.D. Reitz, Combust. Flame 153 (2008) 216-227.

[47] L.M. Pickett, D.L. Siebers, Int. J. Engine Res. 7 (2006) 103-130.

[48] L.M. Pickett, J. Manin, C.L. Genzale, D. Siebers, M.P.B. Musculus, C.A. Idicheria, SAE Int. (2011) 2011-01-0686.

[49] M. Bolla, Y.M. Wright, K. Boulouchos, G. Borghesi, E. Mastorakos, Combust. Sci. Technol. 185 (2013) 766-793.

[50] B.F. Kock, B. Tribalet, C. Schulz, P. Roth, Combust. Flame 147 (2006) 79-92.

[51] J. Johnsson, H. Bladh, P.-E. Bengtsson, Appl. Phys. B 99 (2010) 817-823.

[52] S. Kook, R. Zhang, K. Szeto, L.M. Pickett, T. Aizawa, SAE Int. J. Fuels Lubr. 6 (2013) 80-97. 